\title{
IMPACT OF MYOCARDIAL BLUSH ON LEFT VENTRICULAR REMODELING IN PATIENTS TREATED SUCCESSFULLY WITH PRIMARY OR RESCUE CORONARY INTERVENTION
}

\author{
Mohamed Wafaie AboulEnin MD ;Mahmoud Diaa Almenshawy MD;Elsayed Mohamed Farag MD and \\ Azza Sadaka Nasif MSc* \\ Cardiology Department, Faculty of Medicine, Zagazig University.
}

\section{ABSTRACT}

Background: Myocardial blush grade (MBG) in patients treated successful primary or rescue percutaneous coronary intervention (PCI) for anterior ST elevation myocardial infarction (STEMI) is a good indicator of microvascular reperfusion that may impact left ventricular $(\mathbf{L V})$ remodeling.

Methods: this study included 60 consecutive patients suffered from anterior STEMI whom primary or rescue PCI were done, we evaluate MBG after primary or rescue PCI immediately . For each patient transthoracic echocardiography was done at 24 hours and repeat after 6 months after PCI for evaluation of LV function and volumes.

Results: patients with myocardial reperfusion MBG ( II-III) after primary or rescue PCI was associated with a highly significantly lower rate of remodeling than the absence of myocardial reperfusion MBG (0-1) (12.1\% vs. $75 \%, P<0.001$ ). also, after 6 months, patients with MBG ( II-III) had significantly smaller LV end-diastolic volume ( $99 \pm 23$ vs. $113 \pm 27 \mathrm{ml})$ compared with patients with MBG (0-1). LV remodeling was defined as an increase in end-diastolic volume (LVED) by more than $20 \%$.

Conclusions: Microvascular reperfusion impairment, that assessed by MBG (0-1) in patients with STEMI treated successfully with primary or rescue PCI may be associated with LV dilatation and remodeling.

Keywords: myocardial blush, remodeling, acute myocardial infarction, primary ,rescue, percutaneous coronary intervention, microvascular reperfusion.

Abbreviations: $\mathrm{LV}=$ left ventricular, $\mathrm{MB}=$ myocardial blush, $\mathrm{PCI}=$ percutaneous coronary intervention ,STEMI = ST elevation myocardial infarction

*Corresponding author: Azza Sadaka Nasif

Received: November 2015

Mobile:+201226630639;

E-mail address: azza.nasif@yahoo.com;

Accepted: January 2016

\section{INTRODUCTION}

$\mathbf{T}$ he advantage of primary or rescue coronary intervention (PCI) in patients with anterior STEMI have been referred to early reperfusion and restoration of thrombolysis in myocardial infarction grade 3 flow in the infarct-related artery ${ }^{[1]}$. However, recent studies were shown a high degree of $\mathrm{LV}$ dilation and remodeling that occurs in patients with STEMI even after successful primary or rescue PCI ${ }^{[2] .}$ Some studied show that restoration and reperfusion of blood flow in the infarct-related artery may be associated with inadequate myocardial perfusion. [3]. The success of STEMI treatment is not justified only by the reperfusion of the infarctrelated artery, but myocardial reperfusion is more important. Inspite of TIMI grade 3 flow, the infarct area may undergo less reperfusion at the level of myocardial tissue because of injury to the microvasculature by obstruction with neutrophil and debris, a phenomenon also known as the "no-reflow" phenomenon ${ }^{[4]}$. So, the angiographic myocardial blush score by contrast at the time of PCI based on the density of the dye and their washout in the infracted myocardium, is shown a simple method that correlates with myocardial tissue perfusion immediately after reperfusion of the infarct-related artery ${ }^{[5] .}$

\section{AIM OF THE WORK}

The aim of this study is to assess the influence of Myocardial Blush Grade on Left Ventricular (LV) dilatation and remodeling in patients with ST elevation myocardial infarction (STEMI) whom undergoing successful primary or rescue PCI in patients.

\section{PATIENTS AND METHODS}

The study conducted in Cardiology department, faculty of medicine, Zagazig University and Damietta cardiac center from February 2014 to April 2015. it included 60 subjects; 53 males, 7 females ,aged 52.88 \pm 8.89 years, with first anterior STEMI, All patients underwent general examination for vital signs (Bp, pulse, RR), and Local cardiac examination (S3 gallop, murmurs), also evaluated for presence of risk factors of IHD (Smoking, Hypertension, Diabetes mellitus, Dyslipidaemia), associated co morbidities , 
Routine laboratory investigations aCardiac biomarkers (total CK\& CK-MB and Troponin). b- Kidney function tests (s. creatinine).c- Lipid profile including (Total cholesterol, low density lipoprotein (LDL), high density lipoprotein (HDL)\&triglycerides) d- Random blood sugar measured on admission * The inclusion criteria : a) patients with anterior wall STEMI (defined as typical chest pain more than 30 minutes and ECG changes ( STsegment elevation more than $2 \mathrm{~mm}$ in two contiguous electrocardiography leads) b) emergency PCI (primary PCI within $120 \mathrm{~min}$. of onset of the symptom or rescue PCI) and c) successful recanalization and reperfusion of the infarct-related artery which assessed by TIMI grade 3 flow and visually assessed by residual stenosis in the infarct-related artery

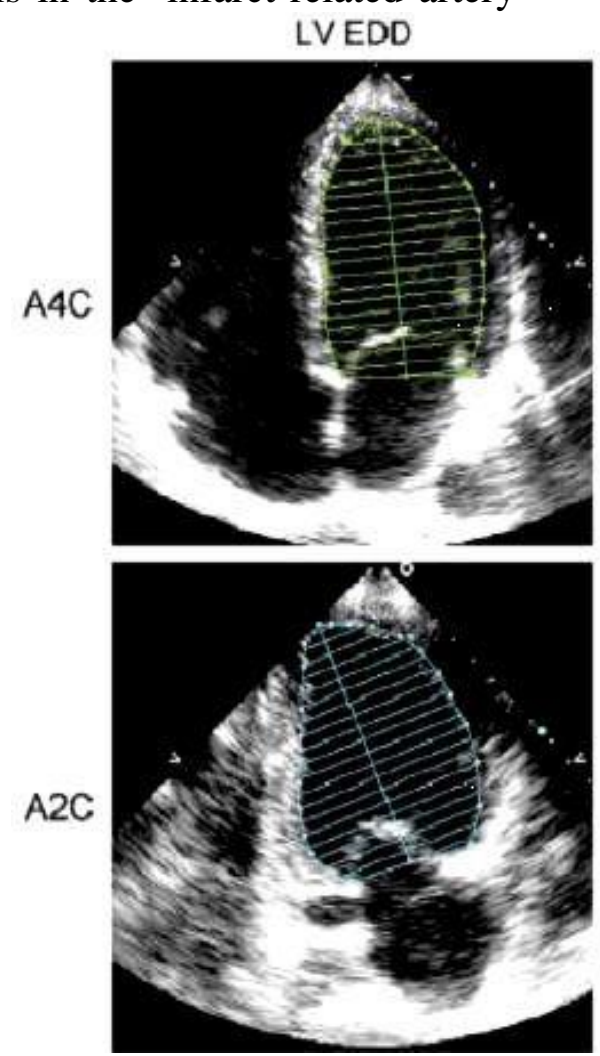

Echocardiographic examinations were performed with the VIVID 9 ultrasound system (GE, Horten, Norway) using 2.5-3.5 MHz transducers and

SIMINS (G 60 S), Transthoracic twodimensional echocardiography and the following data of the left ventricle will be determined: LVED volume, LVES volume and $\mathrm{EF} \%$ will be calculated using Simpson's rule .LV remodeling defined as an increase in LVEDV more than $20 \%$ six

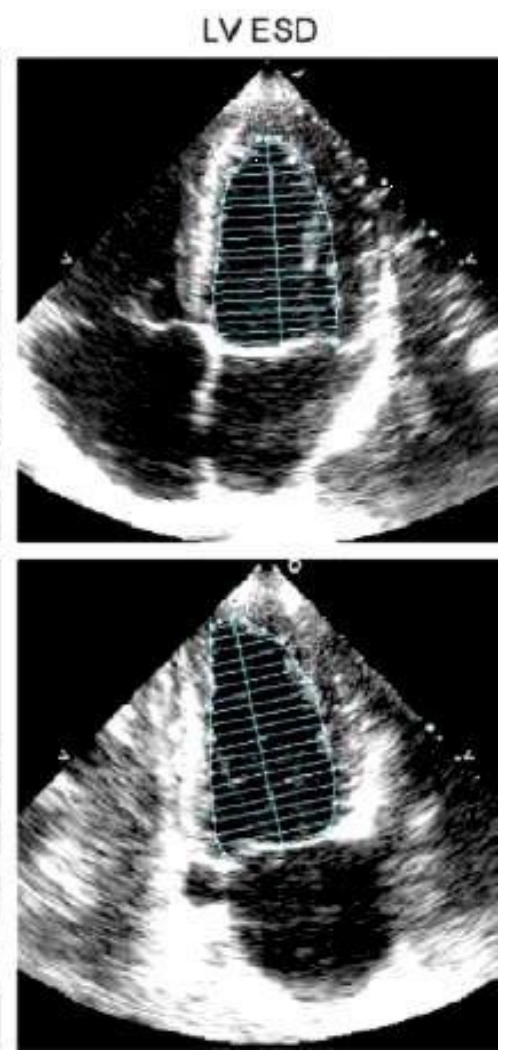

less than $20 \%$. *The exclusion criteria were: a) valvular heart disease; and b) technically poor window for transthoracic twodimensional echocardiography. The studied patients underwent 2-D echocardiography within 24 hours of the PCI and repeat after 6 months .

The study protocol was approved by the institutional ethics committee and all patients gave informed consent.

\section{- Surface ECG}

Standard 12 leads surface ECG was performed for all patients, immediately on admission and subsequently every 6 hours during first 24 hours, and once daily until discharge.

\section{- Echocardiography}


units) bolus dose was injected after sheath insertion. The procedure was performed according to the standard technique of PCI. Femoral approach was the standard in all patients using 6-7 Fr sheath. Diagnostic coronary angiography was done to detect the culprit vessel. XB or JL guide catheters were used during PCI. Aspiration devices and glycoproteinsIIb/IIIa inhibitors were used in lesions with heavy thrombus burden and or impaired TIMI flow after PCI. The operator determined the size and length of the stent, the sheath was removed 6 hours later from the end of PCI and compression was done manually. TIMI flow grade and MBG will be assessed on the angiograms taken shortly after PCI in the best view showing the infarct-related artery ${ }^{\text {[7]. }}$ For MBG, we require ten seconds of cine filming to allow filling of the venous system that required to evaluate the washout phase of contrast dye.
Myocardial blush grade (MBG) is an angiographic measure of myocardial perfusion at the capillary level ${ }^{[8]}$.

\section{- Statistical Analysis}

Data checked, entered and analyzed by SPSS version 20. Data were expressed as mean \pm SD for quantitative values, numbers and percentage for categorical variables. ANOVA (f test), paired-t test, Chi-square $\left(\mathrm{x}^{2}\right)$ and Pearson's' correlation $r$ were used when appropriate. We considered results statistically significant when $p$ value $\leq 0.05$.

\section{RESULTS}

The baseline demographic, clinical parameters of studied groups are shown in Table (1). There were no significant differences between four groups regarding; age, sex, , dyslipedemia, DM, hypertension, smoking and family history (P-value>0.05).

Table (1): Baseline characteristic and MBG:

\begin{tabular}{|c|c|c|c|c|c|c|c|}
\hline & & Grade 0 (12) & Grade I (14) & $\begin{array}{ll}\text { Grade } & \text { II } \\
(20) & \\
\end{array}$ & Grade III (14) & & P-value \\
\hline Age & $\begin{array}{l}\text { Mean } \\
\pm \text { SD }\end{array}$ & $56.3 \pm 7.1$ & $57.3 \pm 3.8$ & $55 \pm 7.9$ & $55 \pm 7.2$ & $\mathrm{~F}=0.4$ & 0.751 \\
\hline FMC & $\begin{array}{l}\text { Mean } \\
\pm \text { SD } \\
\end{array}$ & $195 \pm 71.7$ & $178.5 \pm 72.1$ & $147.8 \pm 66$ & $121.4 \pm 39.1$ & $\mathrm{~F}=3.5$ & 0.02 \\
\hline \multirow{2}{*}{ Sex } & Male & $11(91.7 \%)$ & $11(78.6 \%)$ & $20(100 \%)$ & $11(78.6 \%)$ & \multirow{2}{*}{$\chi^{2}=5.3$} & \multirow{2}{*}{0.147} \\
\hline & Female & $1(8.3 \%)$ & $3(21.4 \%)$ & $0(0 \%)$ & $3(21.4 \%)$ & & \\
\hline \multicolumn{2}{|c|}{ Hypretension } & $9(75 \%)$ & $7(50 \%)$ & $14(70 \%)$ & $10(71.4 \%)$ & $\chi^{2}=2.4$ & 0.499 \\
\hline \multicolumn{2}{|l|}{ DM } & $7(58.3 \%)$ & $7(50 \%)$ & $13(65 \%)$ & $10(71.4 \%)$ & $\chi 2=1.5$ & 0.677 \\
\hline \multicolumn{2}{|c|}{ Smoking } & $11(91.7 \%)$ & $9(64.3 \%)$ & $19(95 \%)$ & $10(71.4 \%)$ & $\chi 2=7$ & 0.072 \\
\hline \multicolumn{2}{|c|}{ Dyslipedemia } & $5(41.7 \%)$ & $6(42.9 \%)$ & $10(50 \%)$ & $8(57.1 \%)$ & $\chi 2=0.8$ & 0.84 \\
\hline \multicolumn{2}{|c|}{ Family history } & $10(83.3 \%)$ & $8(57.1 \%)$ & $12(60 \%)$ & $9(64.3 \%)$ & $\chi 2=2.4$ & 0.498 \\
\hline
\end{tabular}

** Time to first medical contact and MBG:

There were a significant difference between four groups regarding first medical contact(FMC), $(\mathrm{P}-\mathrm{value}<0.05)$ there was significant difference between different MBG with inverse correlation between time to FMC and MBG figure (1). 


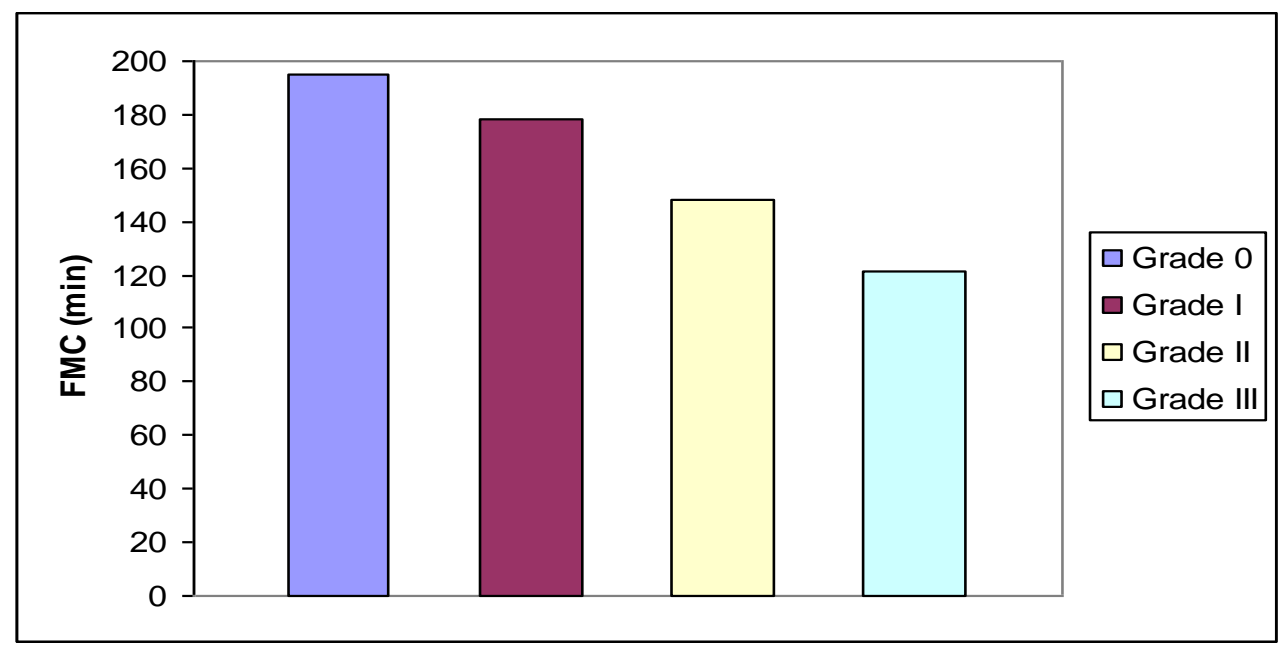

Figure (1): Time to first medical contact and MBG

**Emergency PCI data and MBG:

There was no significant difference between four groups regarding type of PCI (Pvalue $=0.469$ ) .rescue PCI was done for 25 cases, 15 of them have good myocardial blush, MBGII and MBG III, Also, there was no significant difference between four groups regarding aspiration (P-value=0.32). There was no significant difference between four groups regarding usage of GPllb/llla inhibitors (P-value=0.423), multivessel PCI were done to 9 patients with significant difference as all patients had MBG II and MBG III Table (2).

Table (2): Emergency PCI data and MBG

\begin{tabular}{|c|c|c|c|c|c|c|c|c|c|c|c|}
\hline \multirow{2}{*}{\multicolumn{2}{|c|}{ Variable }} & \multicolumn{2}{|c|}{$\begin{array}{l}\text { Grade } \\
\text { (12) }\end{array}$} & \multicolumn{2}{|c|}{$\begin{array}{l}\text { Grade } \\
\text { (14) }\end{array}$} & \multicolumn{2}{|c|}{$\begin{array}{l}\text { Grade } \\
\text { (20) }\end{array}$} & \multicolumn{2}{|c|}{$\begin{array}{l}\text { Grade III } \\
\text { (14) }\end{array}$} & \multirow[t]{2}{*}{$\chi^{2}$} & \multirow[t]{2}{*}{$\begin{array}{l}\text { P- } \\
\text { value }\end{array}$} \\
\hline & & No & $\%$ & No & $\%$ & No & $\%$ & No & $\%$ & & \\
\hline \multirow{2}{*}{$\begin{array}{l}\text { Type of } \\
\text { PCI }\end{array}$} & 1ry & 8 & 66.7 & 8 & 57.1 & 12 & 60 & 7 & 50 & \multirow{2}{*}{0.774} & \multirow{2}{*}{0.855} \\
\hline & Rescue & 4 & 33.3 & 6 & 42.9 & 8 & 40 & 7 & 50 & & \\
\hline \multicolumn{2}{|l|}{ Aspiration } & 4 & 33.3 & 9 & 64.3 & 8 & 40 & 9 & 64.3 & 3.5 & 0.32 \\
\hline \multicolumn{2}{|c|}{$\begin{array}{l}\text { Use of GPIlb/llla } \\
\text { inhibitors }\end{array}$} & 2 & 16.7 & 3 & 21.4 & 6 & 30 & 1 & 7.1 & 2.8 & 0.423 \\
\hline \multicolumn{2}{|c|}{ Multivessel PCI } & 0 & 0 & 0 & 0 & 3 & 15 & 6 & 42.9 & 13.1 & 0.004 \\
\hline
\end{tabular}

\section{Emergency PCI data and remodeling: **}

$13(61.9 \%)$ of patients who undergo primary PCI had remodeling versus $8(38.1 \%)$ of patients who undergo rescue PCI (Pvalue $=0.286) .10(47.6 \%)$ of patients who undergo thrombus aspiration had remodeling versus $20(51.3 \%)$ of patients who didn't have remodeling $(\mathrm{P}$-value $=0.787) .3(14.3 \%)$ of patients who used Glycoprotein IIb/IIIa inhibitors had remodeling versus $9(23.1 \%)$ of patients who didn't have remodeling (Pvalue $=0.417$ ) Table (3). 
Table (3): Emergency PCI data and remodeling.

\begin{tabular}{|c|c|c|c|c|c|c|c|}
\hline \multirow{2}{*}{ Variable } & & \multicolumn{2}{|c|}{$\begin{array}{l}\text { Remodeling } \\
(21)\end{array}$} & \multicolumn{2}{|c|}{$\begin{array}{l}\text { No Remodeling } \\
(39)\end{array}$} & \multirow{2}{*}{$\chi^{2}$} & \multirow{2}{*}{ P-value } \\
\hline & & No & $\%$ & No & $\%$ & & \\
\hline \multirow[t]{2}{*}{ Type of PCI } & $\begin{array}{l}\text { Primar } \\
\mathbf{y}\end{array}$ & 13 & 61.9 & 22 & 56.4 & \multirow[t]{2}{*}{1.13} & \multirow[t]{2}{*}{0.287} \\
\hline & Rescue & 8 & 38.1 & 17 & 43.5 & & \\
\hline Aspiration & & 10 & 47.6 & 20 & 51.3 & 0.073 & 0.787 \\
\hline $\begin{array}{l}\text { Use of } \\
\text { inhibitors }\end{array}$ & GPIlb/llla & 3 & 14.3 & 9 & 23.1 & 0.659 & 0.417 \\
\hline Myocardial & ush & 1 & 4.8 & 31 & 79.5 & 30.624 & 0.000 \\
\hline
\end{tabular}

**Echocardiographic data and MBG:

-End diastolic volume (EDV). At 24 hours post PCI, there was significant difference between four groups regarding EDV (p-value 0.028). After 6 months, there was significant difference between four groups regarding EDV (p-value 0.001).

-End systolic volume (ESV). At 24 hours post PCI, there was significant difference between four groups regarding ESV (p-value 0.048). After 6 months, there was significant difference between four groups regarding ESV (p-value 0.000).

Table (4): Echocardiographic data and MBG
-Ejection fraction (EF). At 24 hours post PCI, there was significant difference between four groups regarding EF (p-value 0.001). After 6 months, there was significant difference between four groups regarding $\mathrm{EF}$ ( $\mathrm{p}$-value 0.0001 )

-Rmodeling defined as $>20 \%$ increase in EDV, $100 \%$ of patients with grade $0 \mathrm{MBG}$ versus $50 \%$ of grade I versus $5 \%$ of grade II versus $7.1 \%$ of grade III MBG had ventricular remodeling at 6 months $\quad(\mathrm{P}-$ value $<0.001)$. Table (4)

\begin{tabular}{llllllll}
\hline Variable & $\begin{array}{l}\text { Grade } \\
(\mathbf{1 2})\end{array}$ & $\begin{array}{l}\text { Grade } \\
(\mathbf{1 4})\end{array}$ & Grade II (20) & $\begin{array}{l}\text { Grade III } \\
(\mathbf{1 4})\end{array}$ & F & P-value \\
\hline $\begin{array}{l}\text { EDV within } \\
\text { (ml) }\end{array}$ & $\mathbf{2 4 h}$ & $115.1 \pm 26.7$ & $110.4 \pm 21.7$ & $114.9 \pm 20.8$ & $93.1 \pm 18.7$ & 3.3 & 0.028 \\
\hline $\begin{array}{l}\text { EDV after 6 months } \\
\text { (ml) }\end{array}$ & $143.4 \pm 23.6$ & $120.9 \pm 32.9$ & $107.6 \pm 26.3$ & $91.9 \pm 21.3$ & 8.9 & 0.0001 \\
\hline $\begin{array}{l}\text { ESV within } \\
\text { (ml) }\end{array}$ & $\mathbf{2 4 h}$ & $60.4 \pm 17.5$ & $55.9 \pm 15.6$ & $46.6 \pm 16.6$ & $44.1 \pm 18.6$ & 2.8 & 0.048 \\
\hline $\begin{array}{l}\text { ESV after 6 months } \\
\text { (ml) }\end{array}$ & $87.8 \pm 17.3$ & $70.8 \pm 29.1$ & $45.8 \pm 23.9$ & $39.7 \pm 15.5$ & 13.3 & 0.0001 \\
\hline EF\% within 24h & $47.4 \pm 7.7$ & $47.4 \pm 8.1$ & $55.3 \pm 9.6$ & $58.3 \pm 7.1$ & 6.2 & 0.001 \\
\hline $\begin{array}{l}\text { EF\% } \\
\text { months }\end{array}$ & $\mathbf{6}$ & $38.9 \pm 4.3$ & $44.2 \pm 10.2$ & $51.2 \pm 9.7$ & $57.8 \pm 9.7$ & 11.1 & 0.0001 \\
\hline Remodeling & $12(100 \%)$ & $7(50 \%)$ & $1(5 \%)$ & $1(7.1 \%)$ & $\begin{array}{l}\chi^{2}= \\
\mathbf{3 6 . 4}\end{array}$ & $<0.001$ \\
\hline
\end{tabular}

EDV:enddiastolic volume, ESV: endsystolic volume, EF: ejection fraction 
Univariate regression analysis

\begin{tabular}{|c|c|c|c|c|c|c|}
\hline & Coefficients & $\begin{array}{l}\text { Standard } \\
\text { Error }\end{array}$ & t Stat & $\mathrm{P}$-value & $\begin{array}{l}\text { Lower } \\
95.0 \%\end{array}$ & Upper $95.0 \%$ \\
\hline AGE & -0.00033 & 0.00612 & -0.05365 & 0.957453 & -0.01266 & 0.011999 \\
\hline Gender & 0.219699 & 0.234781 & 0.935763 & 0.35439 & -0.25317 & 0.692571 \\
\hline HTN & -0.01879 & 0.121191 & -0.15508 & 0.87745 & -0.26289 & 0.225296 \\
\hline$\overline{D M}$ & -0.03843 & 0.100246 & -0.38336 & 0.70326 & -0.24033 & 0.163475 \\
\hline Dyslipidemic & 0.193809 & 0.101597 & 1.907626 & 0.062834 & -0.01082 & 0.398436 \\
\hline Smoking & 0.324755 & 0.185104 & 1.754445 & 0.086162 & -0.04806 & 0.697574 \\
\hline FamilyHx & 0.186623 & 0.10924 & 1.708383 & 0.094456 & -0.0334 & 0.406643 \\
\hline time to FMC & 0.000732 & 0.000368 & 1.986952 & 0.053036 & -0.25987 & 0.001473 \\
\hline troponin i & 0.021504 & 0.00772 & 2.785669 & 0.007791 & 0.005956 & 0.037052 \\
\hline peak CK & -0.00011 & 0.00021 & -0.50585 & 0.615433 & -0.00053 & 0.000317 \\
\hline $\begin{array}{ll}\text { peak } & \text { CK } \\
\text { MB } & \end{array}$ & 0.000608 & 0.00074 & 0.821632 & 0.415619 & -0.00088 & 0.002099 \\
\hline $\begin{array}{l}\text { stent } \\
\text { diameter }\end{array}$ & 0.051241 & 0.176182 & 0.29084 & 0.77251 & -0.30361 & 0.406089 \\
\hline stent length & 0.010513 & 0.011777 & 0.892708 & 0.376763 & -0.01321 & 0.034233 \\
\hline MBG & -0.1462 & 0.069158 & -2.11404 & 0.040086 & -0.28549 & -0.00691 \\
\hline
\end{tabular}

\section{DISCUSSION}

Ischemic heart disease (IHD) is the main cause of mortality in developed countries and its prevalence is increasing in developing countries [9]. Current therapy of acute myocardial infarction (AMI) is represented by early reperfusion of the myocardium., in some patients, successful restoring of the coronary artery after primary coronary intervention (PCI) is not associated with adequate perfusion of the ischemic myocardium [10[. Srinivasan et al, reported that a significant percentage of patients with ST-elevation myocardial infarction were had impairment of microvascular blood flow inspite of successful reperfusion and patency of the infarct-related artery. Microvascular impairment has been associated with a larger infarct size, heart failure, and death. It still unclear whether this association were due to direct mechanistic significance or whether the microvascular impairment is an epiphenomenon and a manifestation of more ischemic insult to the ischemic myocardium ,Although several mechanisms have been proposed for the microvascular impairment ,distal microembolization during mechanical reperfusion is likely to be an important factor [11] Myocardial blush grade (MBG) now is routinely used to assess the degree of myocardial reperfusion. ${ }^{[12]}$. Marthe et al, reported that MBG should be documented, with TIMI flow grade, at primary PCI in patients with STEMI in standard PCI reports in routine clinical practice ${ }^{[13]}$

The present study shows that the presence of myocardial reperfusion (MBG IIIII) after emergency PCI was associated with a significantly lower rate of $\mathrm{LV}$ dilatation and remodeling than the absence of myocardial reperfusion (MB 0-1) .

In the present study, age of studied patients ranged from 29 to 70 years with a mean of 52 years and there was no significant variance between different MB grades. Males represented $88 \%$. This was in agreement with Korosoglou et al, [14] who reported non significant difference between MBG 0, I, II and III as regard age or sex distribution. In addition Marra et al, ${ }^{[10]}$ reported that no 
significant difference between groups as regard age and sex distribution and MBG and these results are in accordance with those of the present work.

In the present study there was no significant difference between different MBG in risk factors of IHD. Similar results are reported by Korosoglou et al, [14] who reported that, there was no significant difference between different grades as regard hypertension, diabetes, elevated lipid levels and history of tobacco use. Similar results are reported by Hamdan et al. ${ }^{[15] . ~ I n ~ a d d i t i o n, ~}$ Porto et al. ${ }^{[16]}$ reported that, there were no significant differences between the groups in the prevalence of risk factors, administration of drugs, or co morbidities, and these results are in agreement with that of the present study.

In the present study, we find that time from symptom onset to first medical contact (FMC) ranged from 50 to 300 minutes with a mean of 182 minutes and there was significant difference between different MBG with inverse correlation between time to FMC and MBG. These results are in accordance with those reported by Hafiz et al, who reported that Shorter pre-hospital delays in ST-elevation myocardial infarction (STEMI) are associated with improved outcomes. Moreover, Koul et al, showed that delays in FMC-to-PCI in excess of 1 hour were a significantly associated with an increase in severe left ventricular dysfunction at discharge and reported an overall significant association between increasing symptom-toPCI delays and 1-year mortality ${ }^{[18]}$ so, A goal of FMC-to-PCI of less than 1 hour might save patient lives

In the present study there was no signigicant difference as regard thrombus aspiration (TA) and MBG this was concordant with Nilsen et al, [19] who reported that in STEMI patients undergoing pPCI, the use of manual TA was associated with improved ST-segment resolution (STR) at discharge, but not with any difference in final TIMI flow and MBG.

Lagerqvist et al reported that aspiration of the thrombus in patients with STEMI before PCI did not decrease the rate of death from any cause, or stent thrombosis, or rehospitalization for myocardial infarction at 1 year according to the one-year follow-up results from the " TASTE Clinical Trials". [20]

In the contrary, Vlaar et al in the TAPAS trial demonstrated that routine use of manual aspiration with the Export catheter compared with PCI alone during PPCI reduced the incidence of the primary outcome of impaired microvascular perfusion $\mathrm{MBG} 0$ or $1^{\text {[21] }}$. After the publication of this trial, both the ESC and ACC/AHA guidelines included a class IIa recommendation for the use of routine thrombectomy during PPCI.

Satoh et al. compare the efficacy of thrombus aspiration with and without usage of distal protection in patients with STEMI by using a filter devise system during primary PCI and conclude that thrombus aspiration with distal protection with a filter devise were more effective than thrombus aspiration alone in preserving the coronary perfusion, although it may not prevents LV remodeling. 22].

In the present study there was no significant difference between MBG and usage of glycoprotein (GP) IIb/IIIa inhibitors $(\mathrm{P}-$ value $=0.4)$. this was concordant with Schulz, et al. who reported that in patients with acute ST-segment elevation myocardial infarction (STEMI) underwent primary coronary interventions (PCI) the upstream usage of abciximab did not reduce the infarct size or improve clinical outcomes after 1 year of primary PCI. ${ }^{[23]}$

On the contrary, Thiele et al. reported that in primary PCI the intracoronary administration of abciximab is more superior to intravenous administration with reflect to infarct size, perfusion and extent of microvascular obstruction ${ }^{[24]}$ this discrepancy may be due to we use intravenous route only in our study not intracoronary.

A nother study by Giuseppe et al, ${ }^{[25]}$ demonstrated the importance of early administration of GpIIb/IIIa inhibitors and it affected by the time from onset of the symptoms to GpIIb/IIIa inhibitors administration, they explained that in STsegment elevation myocardial infarction a time-dependent composition of the coronary thrombus with more platelets in the first hours - they showed that in patients performed 
primary angioplasty, time from onset of the symptoms to GpIIb/IIIa administration, severely impacts on distal embolization, myocardial perfusion ( $\mathrm{MBG}$ ), and long-term survival. this discrepancies was due to upstream usage of GpIIb/IIIa inhibitors.

In the present study, complete revascularization occur in 9 patients with significant difference with $\mathrm{MBG}$ as all patients have MBG II-III. This was concordant with Engstrøm et al, ${ }^{[26]}$ in DANAMI3-PRIMULTI trial, it concluded that complete revascularization resulted in a lower risk of the primary composite endpoint (all-cause death, nonfatal MI, and ischemiadriven revascularization (PCI or CABG) of non-IRA lesions compared with IRA PCI, but this was driven by a lower rate of repeat revascularization. No differences were seen between the groups with regard to nonfatal MI or mortality. On the contrary, Goldstein et $\mathbf{a l},{ }^{[27]}$ reported that PCI of non-infarct artery is not indicated and harmful unless multiple complex lesions are seen on angiography, these depend on clinical stability of the patient which defined as hypotension, low output , apparent shock, ventricular arrhythmias or symptomatic tachyarrhythmias, and recurrent ischemia.Also, Hamdan et $\mathbf{a l}^{[15]}$ and Vlaar et

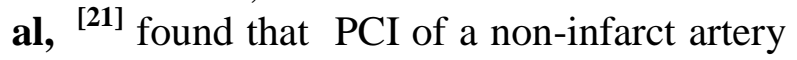
(at the time of primary PCI) were associated with worse clinical result if done in stable patient.

In the present study there was significant increase of EDV at 6 months when compared to their values at 24 hours in MBG 0 and in MBG I, However, there was nonsignificant changes in EDV in patients with MBG II and III. In addition, changes in ESV and LVEF were in correlation with that of EDV.

In the present study rescue PCI cases have better myocardial blush and no remodeling present in more $60 \%$ of them but without significant difference and this reflect that rescue PCI is safe as well as primary PCI.

The predictors of remodeling were impaired myocardial blush and increase cardiac Troponine

These results reflects an inverse relationship between MBG grades and cardiac remodeling (with increased grade, remodeling decreased). These results are in agreement with that reported by Hamdan et al, ${ }^{[15]}$ who reported that, at 6 months, patients with MBG II-III had significantly smaller LVED and LVES volumes, and significantly higher LV ejection fraction (EF) compared with patients with MBG 0-1. In addition, van 't Hof et al' [8] and Hoffmann et al, [28] reported significant increase of EF\% in MBG II-III in comparison to MBG $0-\mathrm{I}$ at the start of the study and at follow up, and these results reflects the good predictability power of MBG in cases before and after angioplasty.

\section{CONCLUSIONS}

Impaired MBG after emergency PCI is associated with increased risk of $\mathrm{LV}$ remodeling. It has the advantage of being simple method to assess myocardial microcirculation.

- Limitations of our study were: (1) Relatively small sample size (2) Short follow up period (3) Heterogenicity of emergency PCI (primary \& rescue).

\section{- Acknowledgement}

We thank the patients for their kind participation in our study.

\section{REFERENCES}

1- Keeley EC, Boura JA, Grines CL. Primary angioplasty versus intravenous thrombolytic therapy for acute myocardial infarction: a quantitative review of 23 randomised trials. Lancet 2003; 361: 13-20.

2- Bolognese L, Neskovic AN, Parodi G, et al. Left ventricular remodeling after primary coronary angioplasty: patterns of left ventricular dilation and longterm prognostic implications. Circulation 2002; 106: 2351-7.

3-Ito H, Tomooka T, Sakai N, et al. Lack of myocardial perfusion immediately after successful thrombolysis. A predictor of poor recovery of left ventricular function in anterior myocardial infarction. Circulation 1992; 85: 1699-705.

4-Brosh D, Assali AR, Mager A, et al. Effect of no-reflow during primary percutaneous coronary intervention for acute myocardial infarction on six month mortality. Am J Cardiol 2007; 99: 442-5.

5-Tsvetkov H, Mosseri M. Myocardial blush grade: an interventional method for assessing myocardial perfusion. IMAJ Isr Med Assoc J 2008; 10: 465-7. 
6-Schiller NB, Shah PM, Crawford M, et al. Recommendations for quantitation of the left ventricle by two-dimensional echocardiography. American Society of Echocardiography Committee on Standards, Subcommittee on Quantitation of TwoDimensional Echocardiograms. J Am Soc Echocardiogr 1989; 2: 358-67.

7-The TIMI Study Group: The Thrombolysis in Myocardial Infarction (TIMI) trial. Phase I findings. TIMI Study Group N Engl J Med 1985; 312: 932-6.

8-van 't Hof AW, Liem A, Suryapranata H, Hoorntje JC, de Boer MJ, Zijlstra F. Angiographic assessment of myocardial reperfusion in patients treated with primary angioplasty for acute myocardial infarction: myocardial blush grade. Zwolle Myocardial Infarction Study Group. Circulation 1998; 97: 2302-6.

9- Modan M, Meytes D, Rozeman P, et al., (1988): Significance of high HbA1 levels in normal glucose tolerance. Diabetes Care; 11:422-8.

10- MarraMB, Corbetti F, Cacciavillani L, et al. Relationship between myocardial blush grades,staining, and severe microvascular damage after primary percutaneous coronary intervention: a study performed with contrast-enhanced magnetic resonancein a large consecutive series of patients. Am Heart J 2010; 159:1124-32

11- Srinivasan M, Rihal C,Holmes D, Prasad A. Adjunctive Thrombectomy and Distal Protection in Primary Percutaneous Coronary Intervention Impact on Microvascular Perfusion and Outcomes 2009 :Circulation (Impact Factor: 14.95); 119(9):1311-9.

12- Henriques JP, Zijlstra F, van 't Hof AW, et al. Angiographic assessment of reperfusion in acute myocardial infarction by myocardial blush grade. Circulation 2003;107:2115-19.

13- MarzilliM,Orsini E, Marraccini $P$, et al. Beneficial effects of intracoronary adenosine as an adjunct to primary angioplasty in acute myocardial infarction.Circulation2000;101:2154-9.

14-Korosoglou G, Haars A, Michael G, et al. Quantitative evaluation of myocardial blush to assess tissue level reperfusion in patients with acute ST-elevation myocardial infarction incremental prognostic value compared with visual assessment. Am Heart J 2007; 153:612-20.

15-Hamdan A, Kornowski R, Sagie A et al. Impact of myocardial blush on left ventricular remodeling after first anterior myocardial infarction treated successfully with primary coronary intervention. IMAJ 2010; 12: 211-15.

16-Porto I, Hamilton-Craig C, Luigi De Maria G, et al. Quantitative Blush Evaluator accurately quantifies microvascular dysfunction in patients with ST-elevation myocardial infarction: Comparison with cardiovascular magnetic resonance. Am Heart J 2011; 162:372-81.e2

17-Hafiz A, Naidu S , DeLeon J, Islam S, Alkhatib A, Lorenz M, D'Elia A, Rosenthal B, Marzo K: Impact of First Medical Contact on Symptom Onset to Door Time in Patients Presenting for Primary Percutaneous Coronary Intervention 2012:Resuscitation Science Symposium. Session XII: Best Original Resuscitation Science Poster Session.

18- Koul S, AndellP,MartinssonA , SmithJ, PalsJ , SchersténF , Jernberg $\mathbf{T}$, Lagerqvist B, Erlinge D.From First Medical Contact to Primary PCI and AllCause Mortality: A Nationwide Study of Patients With ST-Elevation Myocardial Infarction 2014; AHA Journals, Interventional Cardiology.

19-Nilsen W.T.D, Mehran R.Wu R.S,Yu j,Nordrehaug e.j,Brodie R.B, Witzenbichler B, Nikolsky E,Fahy Mand Gregg W. Stone G.W. Coronary reperfusion and clinical outcomes after thrombus aspiration during primary percutaneous coronary intervention: Findings from the HORIZONS-AMI trial ;Catheterization and Cardiovascular Interventions 2013. Coronary Artery Disease ;82( 4)p:594-601.

20- Lagerqvist B, Fröbert $O$, Olivecrona G, GudnasonT, Maeng M, AlströmP, Andersson J, Calais F, CarlssonJ, Collste O, Götberg M, Hårdhammar P, Ioanes D, Kallryd A, M Linder R, Lundin A, Odenstedt J, Omerovic E, Puskar V, Tödt T, Zelleroth E, Östlund $O$, James $S$. Outcomes 1 Year after Thrombus Aspiration for Myocardial Infarction.N Engl J Med 2014; 371:1111-1120.

21- Vlaar PJ, Mahmoud KD, Holmes DR Jr., van Valkenhoef $G$, Hillege HL, van der,Horst IC, Zijlstra F, de Smet BJ. Culprit vessel only versus multivessel and staged percutaneous coronary intervention for multivessel disease in patients presenting with ST-segment elevation myocardial infarction: a pairwise and network meta- 
analysis. J Am Coll Cardiol 2011;58:692703.

22- Satoh S , Inoue H , Omura S , Ejima E , Shimozono $\mathbf{K}$, Hayashi M, Mori $\mathbf{T}$ ,TakenakaK , Kawamura N, Numaguchi K,Mori E , Asoh A ,Nakamura $\mathbf{T}$, Hiyamuta K. Comparison of the Reperfusion Efficacy of Thrombus Aspiration With and Without Distal Protection During Primary Percutaneous Coronary Intervention in Patients With Acute ST-Segment Elevation Myocardial Infarction. The American Journal of Cardiology 2013;112 ( 11) 1725-1729.

23-Schulz S, Birkmeier KA, Ndrepepa G, Moshage W, Dotzer F, Huber K, Dirschinger J, Seyfarth M, Schömig A, Kastrati A, Mehilli J. One-year clinical outcomes with abciximab in acute myocardial infarction: results of the BRAVE3 randomized trial. Clin Res Cardiol. 2010 ;99(12):795-802.

24- Thiele H , FriedenbergerJ, Eitel I , Fürnau G , GrebeE , Erbs S,LinkeA, MöbiusWinklerS , KivelitzD ,Schuler G. Intracoronary Compared With Intravenous Bolus Abciximab Application in Patients
With ST-Elevation Myocardial Infarction Undergoing Primary Percutaneous Coronary Intervention CIRCULATION 2008 Interventional Cardiology.

25-Giuseppe T, Massimo N, Nicola G, Enrico F, Perazzolo M,Cacciavillani, C, Claudio B, Elena O, Filippo C, Giuseppe M,Francesco C, Renato R, Sabino I .Impact of multivessel coronary artery disease on early ischemic injury, late clinical outcome, and remodeling in patients with acute myocardial infarction treated by primary coronary angioplasty Coronary Artery Disease: 2010 ;21 ( 2 ) 78-86.

26-Engstrøm and colleagues. DANAMI3PRIMULTI: Complete Revascularization Improves Outcomes for STEMI;2015

27-Goldstein JA, Demetriou D, Grines CL. Multiple complex coronary plaques in patients with acute myocardial infarction. $\mathrm{N}$ Engl J Med. 2000;343:915-22.

28-Hoffmann R, Haager P, Christott JA, et al. Usefulness of myocardial blush grade early and late after primary coronary angioplasty for acute myocardial infarction in predicting left ventricular Function. Am J Cardiol 2003;92:1015-19. 